\title{
THE ULTRASTRUCTURAL LOCALIZATION OF SEROTONIN IMMUNOREACTIVITY WITHIN THE NUCLEUS OF THE SOLITARY TRACT OF THE CAT ${ }^{1}$
}

\author{
BRUCE MALEY² AND ROBERT ELDE
}

Department of Anatomy, University of Minnesota, Minneapolis, Minnesota 55455

Received February 5, 1982; Revised May 6, 1982; Accepted May 7, 1982

\begin{abstract}
Using a modification of the peroxidase-antiperoxidase technique, serotonin immunoreactivity was localized at the ultrastructural level in the nucleus of the solitary tract of the cat. Structures containing serotonin immunoreactivity included unmyelinated axons, varicosities $(0.5$ to $2 \mu \mathrm{m}$ in diameter), and synaptic terminals. The serotonin-containing synaptic terminals were found less frequently than axons or varicosities. Within unmyelinated axons and varicosities, the immunoreactivity was associated mainly with large granular vesicles $(80$ to $150 \mathrm{~nm})$. While large granular vesicles were found in all immunoreactive structures, greater numbers were observed in axons and nonsynaptic varicosities. Serial sections of several nonsynaptic serotonin-immunoreactive varicosities indicated the lack of synaptic specializations associated with these structures. In a typical section, only one or two granular vesicles were in synaptic terminals which contained numerous small clear vesicles. Serotonin-immunoreactive terminals formed asymmetrical contacts with dendrites and spines. No synaptic contacts involving immunoreactive terminals were found on cell bodies or other axonal structures. Serotonin-containing neuronal perikarya within the nucleus of the solitary tract were never observed.

The abundance of nonsynaptic varicosities containing large granular vesicles suggests a possible neurohumoral role for serotonin within the feline nucleus of the solitary tract. This is discussed in relation to previous reports concerning the paucity of genuine synaptic contacts involving serotonin in other regions of the central nervous system. The presence of serotonin-immunoreactive terminals in the nucleus of the solitary tract also suggests its function as a putative neurotransmitter.
\end{abstract}

The distribution of serotonin (5-hydroxytryptamine; 5 HT) within the central nervous system of the rat and the cat has been well documented at the light microscopic level using formaldehyde-induced fluorescence (Dahlstrom and Fuxe, 1964; Sladek and Garver, 1976; Crutcher and Humbertson, 1978; Poitras and Parent, 1978; Schofield and Everitt, 1981), selective destruction of monoamine neurons via 5,6-dihydroxytryptamine (Aghajanian et al., 1973; Ajika and Ochi, 1978), specific uptake of

\footnotetext{
'We would like to thank Drs. Virginia Seybold, Vicky Holets, and Marty Wessendorf for their helpful suggestions during the preparation of the manuscript. In addition, we appreciate the assistance of Mr. Terrence Mullett, Ms. Debra Erickson, and Ms. Kaye Springman. Portions of this investigation were supported by National Institute of Drug Abuse Grant DA 02148 (R. E.), a Scholars Award in Neuroscience from the McKnight Foundation (R. E.), and Diabetes Training Grant 5T32 AM07196 (B. M.).

${ }^{2}$ To whom correspondence should be addressed at his present address: Department of Anatomy, Chandler Medical School, University of Kentucky, Lexington, KY 40536-0084.
}

radiolabeled 5-HT (Beaudet and Descarries, 1978, 1979; Moore et al., 1978; Ruda and Gobel, 1980; Parent et al., 1981), and immunohistochemistry (Steinbusch et al., 1978; Lidov et al., 1980; Steinbusch, 1981; Maley and Elde, 1982). Localization of 5-HT at the ultrastructural level has been hampered by the lack of a specific electrondense marker which is compatible with routine cytological fixatives. A number of investigators have utilized potassium permanganate to detect the general family of monoamine-containing terminals (Richardson, 1966; Hokfelt, 1968; Takahashi et al., 1980). Monoamine terminals also have been identified using false transmitters, such as 5-hydroxydopamine (5-OHDA) and 6-hydroxytryptamine (6-HT; Ajika and Hokfelt, 1973; Chiba and Doba, 1975, 1976), or by their selective destruction with the neurotoxin, 5,6-dihydroxytryptamine (5,6-DHT) Baumgarten et al., 1971; Akija and Ochi, 1978). However, the potassium permanganate fixative alters the morphological appearance of the neuropil and makes comparison with conventionally fixed tissue difficult. In the case of false transmitters like 5-OHDA or 6-HT, it is possible 
they are taken up nonspecifically and may not represent terminals containing a specific monoamine. While 5,6DHT allows the use of conventional fixatives, it is based on the degeneration of a terminal for positive identification of a 5-HT-containing structure. Unfortunately, in many instances, the neurotoxin-induced changes make a morphological evaluation difficult. The identification of presumed 5-HT structures has been accomplished via selective uptake of radiolabeled 5-HT (Aghajanian and Bloom, 1967; Beaudet and Descarries, 1979; Descarries et al., 1975; Ruda and Gobel, 1980; Ruda et al., 1981). However, the development of antibodies directed against 5 -HT has made possible the localization of 5-HT immunoreactivity using both the immunofluorescence and the peroxidase-antiperoxidase (PAP) techniques. The PAP procedure not only is useful at the light microscopic level but has been shown to be useful in demonstrating chemically coded neurons at the ultrastructural level (Pelletier et al., 1974; Pickel et al., 1975; Barber et al., 1979).

Using immunohistochemical techniques, 5-HT-like immunoreactivity has been reported in the nucleus of the solitary tract of the rat (Steinbusch, 1981) and the cat (Maley and Elde, 1982) at the light microscopic level. The ultrastructural features of serotonergic elements within the nucleus of the solitary tract have not been reported. Serotonin has been reported to be involved in the regulation of respiration (Eldridge and Millhorn, 1981) and blood pressure (Wolf et al., 1981), therefore implicating 5-HT as a putative neurotransmitter or neuromodulator. Since the nucleus of the solitary tract is an important center in processing respiratory and cardiovascular input to the central nervous system, the purpose of the present investigation was to study the distribution of 5-HT at the electron microscopic level using a modification of the PAP procedure (Sternberger, 1979) in order to determine the possible morphological basis for its effects.

\section{Materials and Methods}

Normal and colchicine-treated $(500 \mu \mathrm{g}$ injected into the cisterna magna $48 \mathrm{hr}$ prior to sacrifice) cats were used in the present study. All animals were obtained from the Research Animal Resources Center at the University of Minnesota. For fixation, each cat was perfused with $500 \mathrm{ml}$ of $0.9 \%$ saline followed by 2.0 liters of $4 \%$ paraformaldehyde, $0.3 \%$ glutaraldehyde in Sörenson's phosphate buffer, $\mathrm{pH} 7.2$. The addition of $0.3 \%$ glutaraldehyde to the fixative solution improved ultrastructural preservation of the tissue and did not noticeably decrease 5-HT immunostaining within the nucleus of the solitary tract when compared to animals perfused with lower quantities of glutaraldehyde. Following the perfusion, the
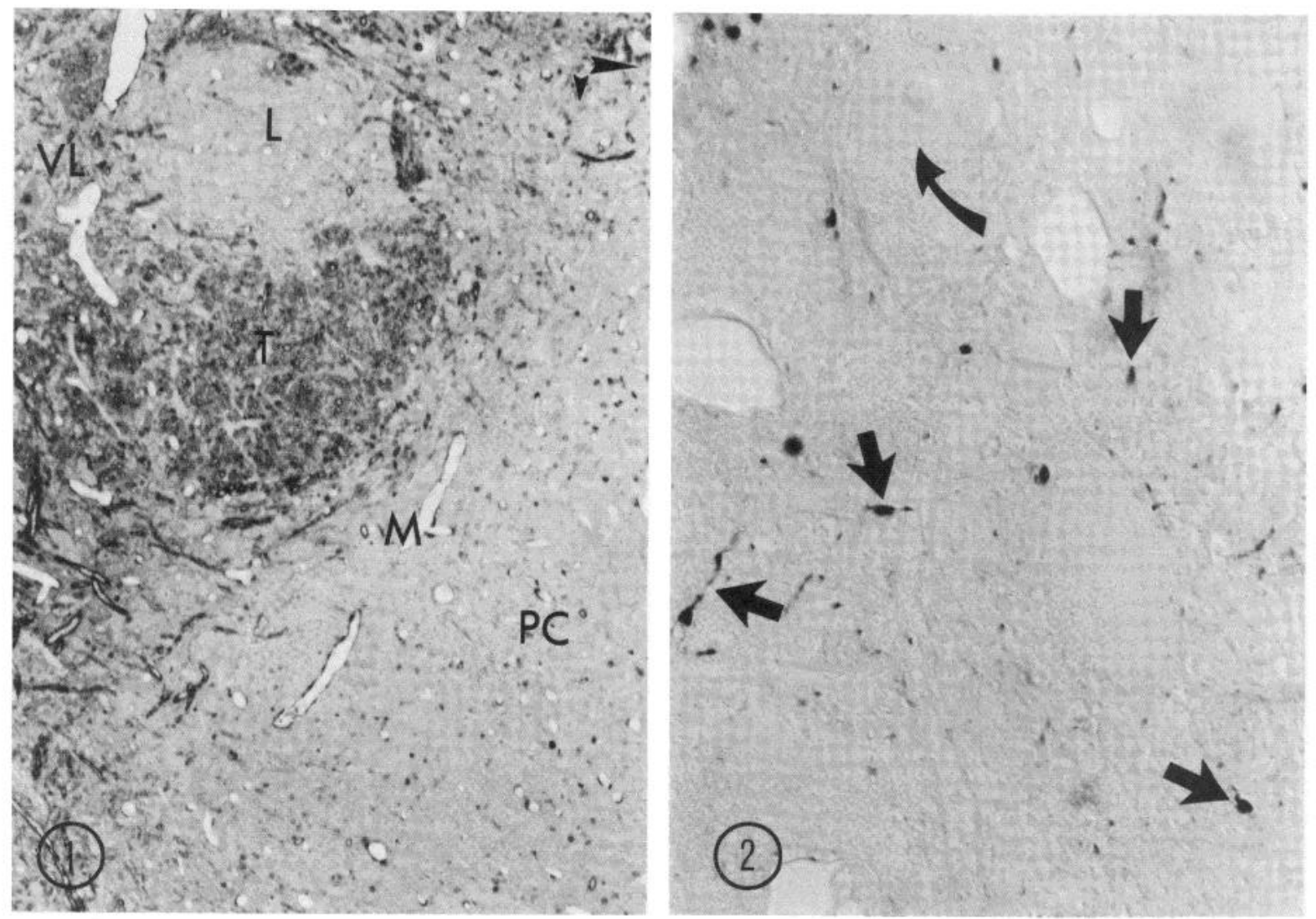

Figure 1. Photomicrograph of a 1- $\mu \mathrm{m}$-thick section of the nucleus of the solitary tract incubated with serotonin antiserum. The tract $(T)$ is indicated along with the medial $(M)$, parvocellular $(P C)$, lateral $(L)$, and ventrolateral $(V L)$ subdivisions. The large and small arrowheads in the upper right corner indicate dorsal and medial, respectively. Final magnification $\times 144$.

Figure 2. Nomarski photomicrograph of a higher magnification of the medical subdivision. Numerous serotonin-immunoreactive structures (arrows) can be seen within the neuropil. An unstained neuron is also visible in the neuropil (curved arrow). Final magnification $\times 455$. 
brain was left in the skull for an additional $90 \mathrm{~min}$. After removal, the brain was placed in fresh fixative overnight at $4^{\circ} \mathrm{C}$. On the next day, the caudal brain stem was isolated and sectioned in the transverse plane on a vibrating microtome containing cold Sörenson's phosphate buffer. Individual $100-\mu \mathrm{m}$ sections were cut and placed into cubicles filled with fresh buffer.

For visualization of the 5 -HT immunoreactivity at the ultrastructural level, a modification of the Sternberger (1979) procedure was used. The sections were incubated in the primary 5 -HT antiserum (1:1000; diluted in phosphate-buffered saline containing $0.3 \%$ Triton X-100) overnight at $4^{\circ} \mathrm{C}$. Sections incubated in the primary 5HT antiserum diluted 1:1000 in phosphate-buffered saline but lacking $0.3 \%$ Triton X-100 exhibited morphological characteristics similar to those treated with the detergent. However, with the addition of $0.3 \%$ Triton X100 , the 5-HT immunostaining extended more deeply into the tissue $(\sim 10 \mu \mathrm{m})$. On the next day, the tissue was rinsed several times with phosphate buffer prior to the application of sheep anti-rabbit IgG (Antibodies, Inc.; $1: 300$ in phosphate buffer). After $1 \mathrm{hr}$, the sections were rinsed as before and then incubated in rabbit PAP (Cappel Laboratories, Inc.; 1:500 in phosphate buffer) for an additional hour. Subsequent to several rinses in phosphate buffer, the tissue sections were reacted with $3,3^{\prime}-$ diaminobenzidine $(50 \mathrm{mg} / 100 \mathrm{ml}$ of phosphate buffer) to which $330 \mu \mathrm{l}$ of $0.3 \% \mathrm{H}_{2} \mathrm{O}_{2}$ was added just prior to use. The reaction was halted with several rinses of phosphate buffer.

Following the immunohistochemical procedure, the tissue was treated with $1 \%$ osmium tetroxide, dehydrated in increasing concentrations of ethanol, and flat embedded in Spurr's resin between slides coated with dimethyldichlorosilane (Sigma). Thick sections of the nucleus of the solitary tract were obtained for purposes of orientation and silver sections were cut, stained with uranyl acetate and lead citrate, and examined with a JEOL 100CX electron microscope. Serial sections through several nonsynaptic 5-HT-immunostained varicosities were examined for the presence of synaptic specializations, which could be missed in single thin sections through the varicosity.

The production and characterization of the 5-HT antiserum has been described elsewhere (Maley and Elde, 1982). In brief, the 5-HT antiserum was found to be specific for serotonin, since it did not cross-react with precursors or metabolites of 5-HT. As an additional test for specificity of the 5-HT antiserum, $1 \mathrm{ml}$ of the working dilution was pretreated for $24 \mathrm{hr}$ with either $10 \mu \mathrm{g}$ of the bovine serum albumin/5-HT conjugate or with free bovine serum albumin. These "absorbed" antisera were

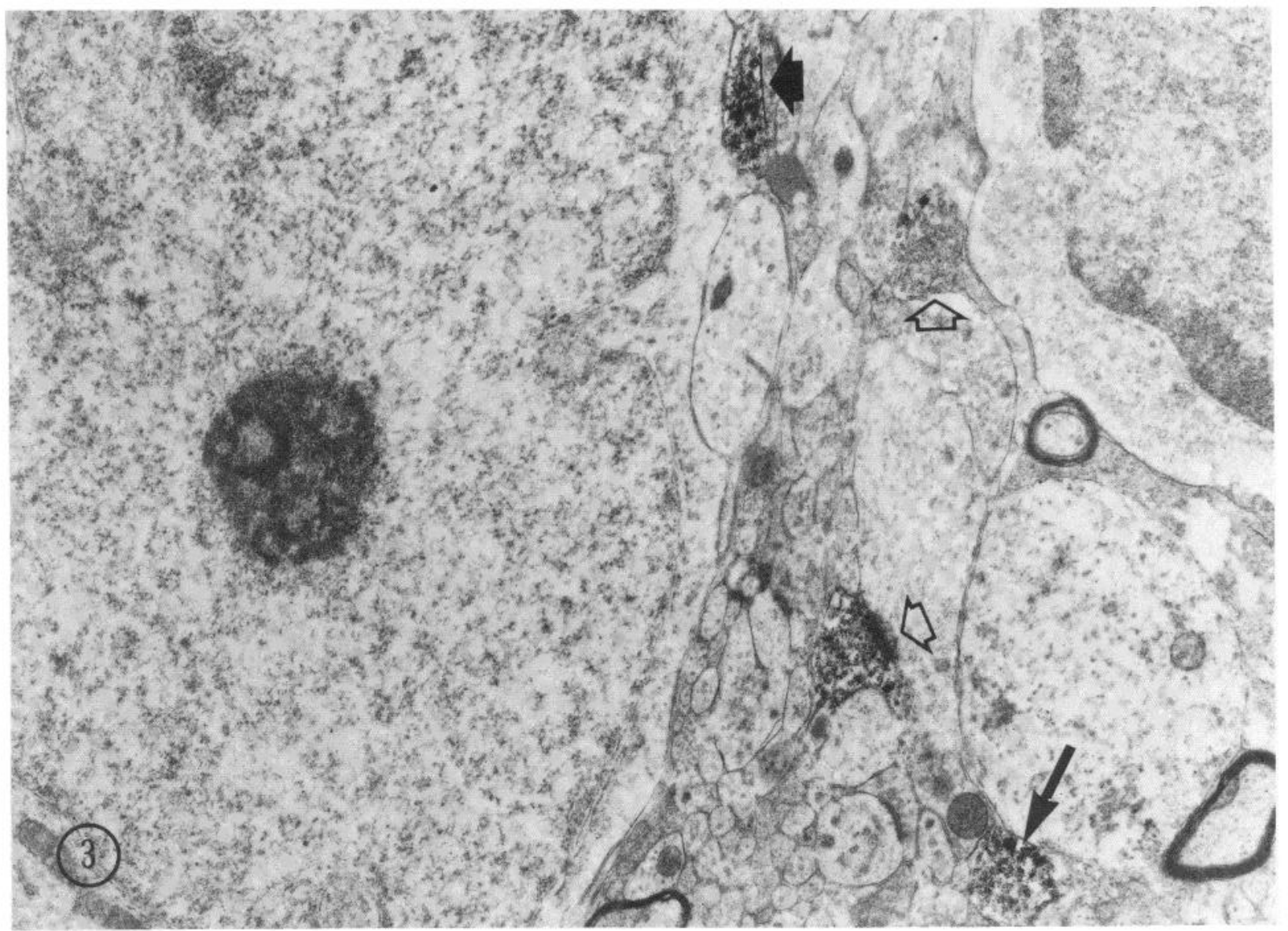

Figure 3. Electron micrograph of serotonin immunoreactivity with the nucleus of the solitary tract. Numerous serotoninimmunoreactive structures, including a varicosity (arrow), fiber (block arrow), and two terminals (open block arrows), are shown. The varicosity and fiber contain numerous large granular vesicles, while the terminals appear to lack the large granular vesicles. Final magnification $\times 10,600$. 
applied to adjacent sections of the nucleus of the solitary tract and run concurrently with the remainder of the tissue. Single sections from these blocks of tissue were examined at both the light and electron microscopic levels for 5-HT immunoreactivity (see Fig. 11).

\section{Results}

At the light microscopic level, examination of $1-\mu \mathrm{m}$ thick sections indicated that the distribution of $5-\mathrm{HT}$ immunoreactivity throughout the nucleus of the solitary tract varied between the subdivisions of the complex. The greatest amount of immunoreactivity was found in the lateral, medial, and dorsomedial band of the parvocellular subdivisions, while lesser amounts of 5-HT immunoreactivity were present in the intermediate, ventrolateral, commissural, and the remainder of the parvocellular subdivisions (Figs. 1 and 2). Although there was variability in the amounts of 5-HT immunoreactivity among the subdivisions at the light microscopic level, examination of thin sections at the ultrastructural level indicated no differences in the types of immunoreactive structures between the various subdivisions of the feline nucleus of the solitary tract. Staining of the tissue was not altered by pretreatment of the antiserum with free bovine serum albumin. However, sections incubated with antiserum pretreated with the bovine serum albumin/5HT conjugate did not exhibit staining at the light or electron microscopic levels.

Within the neuropil of the nucleus of the solitary tract, numerous, small, unmyelinated axons $(0.1$ to $0.5 \mu \mathrm{m}$ in diameter) contained reaction product (Figs. 3, 4, and 5).
The reaction product was associated with microtubules and, occasionally, mitochondria or large granular vesicles ( 80 to $150 \mathrm{~nm}$ in diameter). Longitudinally cut, unmyelinated axons which contained varicosities along their length were encountered occasionally. The reaction product could be seen to occupy the varicosity as well as the nonvaricose portion of the axon and was associated with cellular organelles. Contained within the varicosities, which measured up to $1 \mu \mathrm{m}$ in diameter, were microtubules, mitochondria, sacs of smooth endoplasmic reticulum, and a variety of vesicles, including small, clear vesicles and large granular vesicles (Figs. 3 and 6 ). The most numerous type of vesicle was the large granular variety, many of which were packed within the varicosity (Figs. 6 and 7). In some varicose axons, the number of large granular vesicles was so great that the immunoreactivity associated with them obscured the remainder of cellular organelles. These varicosities did not exhibit synaptic contact with other neuronal structures in the neuropil. While longitudinally cut axons possessing varicosities were encountered within the neuropil only occasionally (Fig. 6), isolated varicosities similar in size and content were found distributed throughout the nucleus of the solitary tract (Figs. 3 and 7). The most prominent characteristic of these structures is the occurrence of numerous large granular vesicles, which occupied the majority of the cytoplasm. Reaction product was always associated with the vesicles. Serial section analysis of several varicosities indicated that they are roughly spherical structures measuring 1.0 to $2.0 \mu \mathrm{m}$ in diameter and normally not in synaptic contact with other neuronal
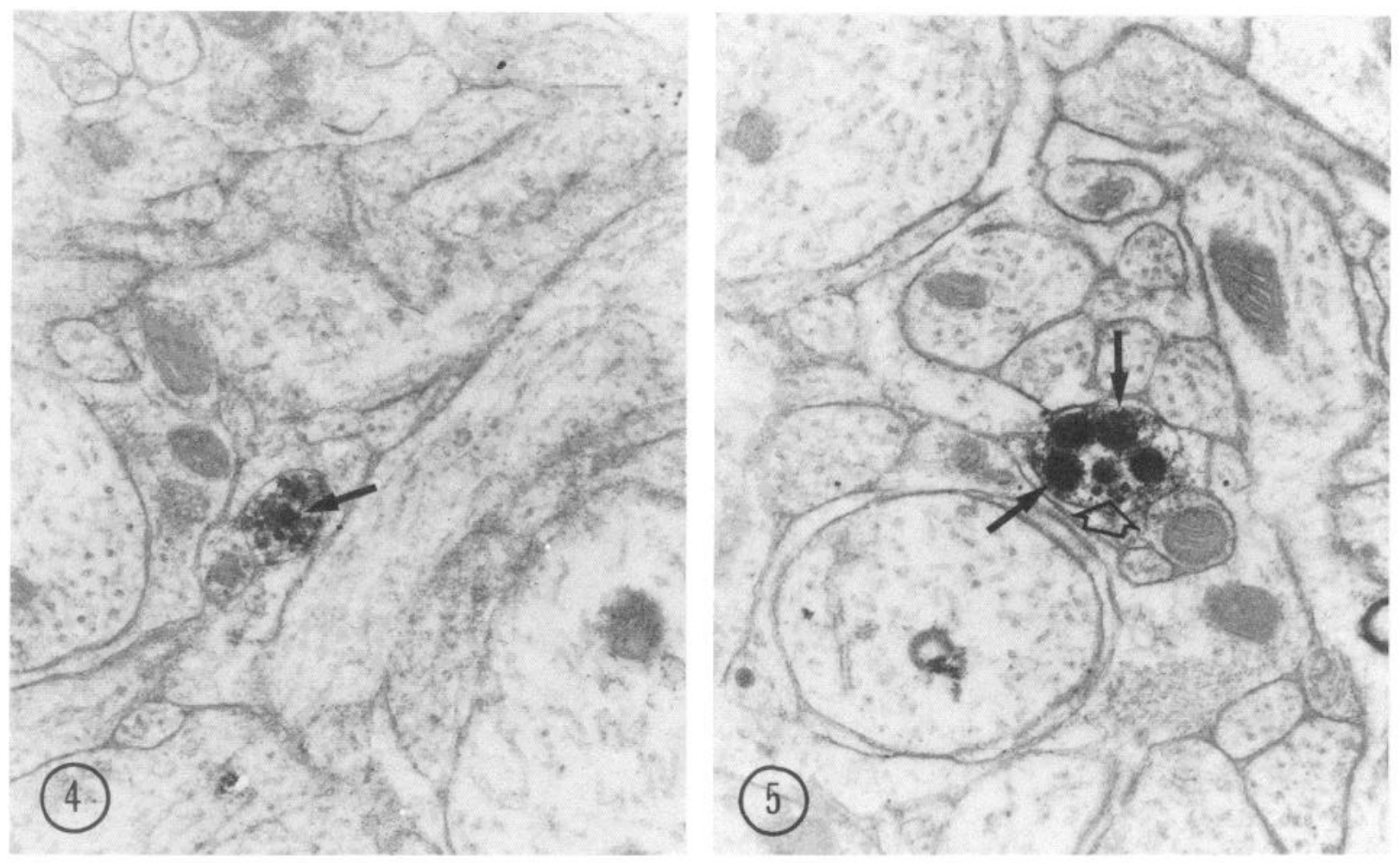

Figure 4. Electron micrograph of a serotonin-immunoreactive axon which contains several large granular vesicles (arrow). Final magnification $\times 36,800$.

Figure 5. Electron micrograph of a small, serotonin-immunoreactive varicosity which contains several large granular vesicles (arrows). Reaction product also can be seen associated with microtubules (open block arrow). Final magnification $\times 39,100$. 
structures. Typically, they were surrounded by glial elements, although, infrequently, they were in apposition to an axon or dendrite. In a single instance, a varicosity was seen adjacent to a neuronal cell body (Fig. 3), although it was not in synaptic contact.

Less frequently encountered were presynaptic terminals containing 5 -HT immunoreactivity within the neuropil of the nucleus of the solitary tract. The terminals measured 0.3 to $1.0 \mu \mathrm{m}$ in diameter and contained mitochondria, large accumulations of small clear vesicles, and an occasional large granular vesicle. Within the synaptic terminal, the PAP reaction product was associated with the membranes of clear synaptic vesicles, mitochondria, and the plasma membrane of the terminal.

The most frequent postsynaptic structures were dendrites, which ranged in size from large primary dendrites ( 2 to $4 \mu \mathrm{m})$ to small, distal dendrites $(0.3$ to $0.6 \mu \mathrm{m})$. The junctional complex was characterized by an asymmetrical density with an accumulation of extracellular material within the synaptic cleft (Figs. 9 and 10). Dendritic spines also received synaptic input from 5-HT-labeled terminals (Fig. 8). As with the case of dendritic contacts, the junctional complex was asymmetrical with a significant accumulation of postsynaptic dense matrix. Appreciable amounts of extracellular material were found within the synaptic cleft. Axosomatic contacts involving 5-HT-immunoreactive terminals were never observed within the nucleus of the solitary tract. In addition, 5-HT-labeled terminals were not presynaptic to other axonal structures. Neither in normal nor colchicine-treated cats was
5-HT immunoreactivity localized to neuronal perikarya or dendritic structures within the nucleus of the solitary tract.

\section{Discussion}

In a previous light microscopic study, we reported a differential distribution of 5-HT-immunoreactive nerve fibers and terminals within the various subdivisions of the nucleus of the solitary tract of the cat (Maley and Elde, 1982). The 5-HT immunoreactivity in that investigation appeared as varicose fibers and punctate structures. The results of the present study at the ultrastructural level confirm the existence of 5-HT immunoreactivity within neuronal structures, including unmyelinated axons, nonsynaptic varicosities, and terminals.

The most striking characteristic of the immunostained structures was the presence of large, granular vesicles $(80$ to $150 \mathrm{~nm}$ ). In the present study, a number of granular vesicles were present in the $5-\mathrm{HT}$ varicosities and small axons, while the 5-HT terminals contained no more than one or two granular vesicles in a given thin section. The paucity of granular vesicles in our study of 5-HT-immunoreactive terminals agrees with previous findings of 5HT-labeled terminals using either the uptake of $\left[{ }^{3} \mathrm{H}\right] 5$ HT (Aghajanian and Bloom, 1967; Chan-Palay, 1976; Descarries et al., 1975; Chan-Palay, 1978; Beaudet and Descarries, 1978; Ruda and Gobel, 1980; Ruda et al., 1981) or the application of monoamine analogues, such as 5-OHDA and 6-HT (Chiba and Doba, 1975; Ajika and Ochi, 1978). While granular vesicles may be associated
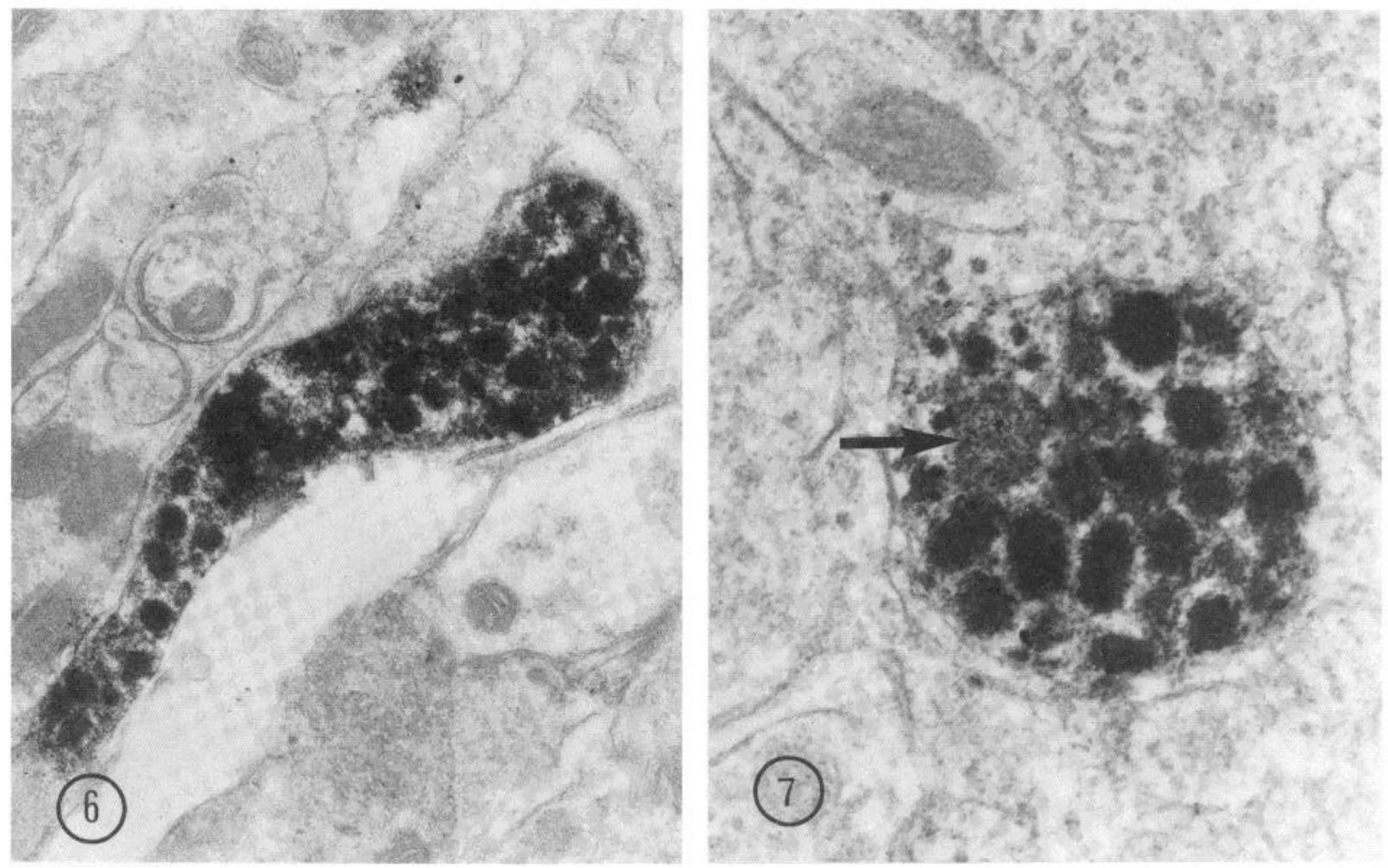

Figure 6. Electron micrograph of a serotonin-immunoreactive axon with a varicosity at one end. Contained within the axon are numerous large granular vesicles. Final magnification $\times 34,000$.

Figure 7. Electron micrograph of a serotonin-immunoreactive varicosity which contains numerous large granular vesicles among several mitochondria (arrow). Final magnification $\times 76,900$. 



Figure 8. Electron micrograph of a serotonin-immunoreactive terminal (solid block arrow) which is presynaptic to a spine. Note the presence of immunoreactivity associated with the membranes of the small clear vesicles and the mitochondria. The synaptic complex is asymmetrical. Final magnification $\times 42,800$.

Figure 9. Electron micrograph of a serotonin-immunoreactive terminal presynaptic to a small dendrite (open block arrow). The axonal terminal contains numerous small clear vesicles and forms an asymmetrical contact with the dendrite. Final magnification $\times 59,000$.

Figure 10. Electron micrograph of a serotonin-immunoreactive profile containing numerous large granular vesicles. Several mitochondria can be seen within the labeled structure (open block arrows). The profile appears to form a synaptic contact with a small dendrite (arrow). Final magnification $\times 68,500$.

Figure 11. Electron micrograph of a varicosity containing numerous large granular vesicles in tissue incubated with serotonin antiserum which was pretreated with the bovine serum albumin/5-HT conjugate. Although inherent density of the vesicles is present, there is no immunoreactivity associated with the vesicles (solid block arrows). Compare the density of these vesicles with the immunoreactive vesicles in Figure 10. Final magnification $\times 59,000$. 
with 5-HT terminals, they are not a requisite for the identification of a 5-HT terminal. Indeed, they appear to be associated with a number of types of monoamine terminals (Chiba and Doba, 1976; Takahashi et al., 1980; Beaudet and Descarries, 1979). The functional significance of granular vesicles within synaptic terminals is not understood at present, although it has been suggested that these vesicles are involved in the storage or transport of 5-HT within the axon (Chan-Palay, 1976). Our morphological studies indicate that granular vesicles may be involved in the transport of 5-HT within the axon, since 5-HT-immunoreactive large granular vesicles were observed most frequently in unmyelinated axons and nonsynaptic varicosities and very seldom were found within terminals. Other investigations also have noted the possibility that granular vesicles act as means to transport 5-HT to the synaptic junctions, where it may be transferred to small vesicles by a means not yet fully understood (Chan-Palay, 1976). Indeed, in the case of our study, 5-HT-immunoreactive boutons contained numerous small clear vesicles and only an occasional large granular vesicle. The rare large granular vesicle within these immunoreactive terminals was not associated with the active zone of the bouton, suggesting that it is not actively involved in the discharge of 5-HT into the synaptic cleft.

A still unresolved question concerning 5-HT-labeled terminals has been the paucity of typical synaptic contacts associated with 5 -HT boutons. Descarries and his colleagues (1975) used the technique of $\left[{ }^{3} \mathrm{H}\right] 5-\mathrm{HT}$ uptake in the rat cerebral cortex and reported very few $(<5 \%)$ synaptic contacts involving 5-HT-labeled terminals. Similarly, 5-HT boutons within the hypothalamus rarely made synaptic contact (Beaudet and Descarries, 1979). In contrast, investigations using the uptake of radiolabeled 5-HT in the dorsal horn of the medulla (Ruda and Gobel, 1980) paratrigeminal nucleus (Chan-Palay, 1978), and cerebellum (Chan-Palay, 1976) noted large percentages of 5-HT profiles exhibiting synaptic contacts. The results of the present study appear to fall in between the two extremes. While we observed a number of 5-HTimmunoreactive terminals, many labeled structures were found not to be in synaptic contact. It has been suggested that the lack of genuine synaptic contacts involving 5HT is due to the small active zone associated with serotonergic terminals. However, serial section analysis of several varicosities located within the nucleus of the solitary tract failed to reveal synaptic junctions associated with these structures. Because our sampling size using serial sections is small (five varicosities), it may be that other 5-HT-immunoreactive varicosities do contain synaptic specializations but were missed in our limited survey.

The apparent disparity of synaptic terminals versus nonsynaptic 5-HT structures throughout various nuclear regions of the central nervous system suggests different functions of 5-HT. It has been suggested that serotonin (or monoamines in general) may be released from nonsynaptic varicosities and act as neurohumors to set or modulate the general activity of the neuronal systems (Chan-Palay, 1978). In the cerebral cortex, 5-HT may, indeed, act more as a neurohumoral agent, thus accounting for the lack of labeled terminals observed there. In the dorsal horn of the medulla, paratrigeminal nucleus, cerebellum, and nucleus of the solitary tract, a variable proportion of 5-HT synaptic terminals occurs. In these regions, 5-HT may function as a neurotransmitter as well as a neuromodulator. Only further investigations can actually resolve these questions.

It has been suggested that $5-\mathrm{HT}$ within the nucleus of the solitary tract may be involved in the facilitation of respiration (Eldridge and Millhorn, 1981) and pressor effects (Wolf et al., 1981). Our studies provide a morphological basis for these observed phenomena. The possible sites of these interactions would be either at the active site of the 5-HT terminals or more diffusely in the vicinity of nonsynaptic varicosities containing 5-HT. In the case of pressor effects of 5-HT, Wolf et al. (1981) reported a rapid increase in blood pressure followed by a gradual decrease over a $15-\min$ period, indicating a relative long term effect of $5-\mathrm{HT}$ on blood pressure. Such a finding may be more consistent with the nonsynaptic release of 5-HT.

This long term effect of 5 -HT on blood pressure suggests a neurohumoral role for 5-HT in the solitary nucleus. The site of 5 -HT release may be the nonsynaptic varicosities which we see in the present study. Release from 5-HT varicosities may allow the 5-HT to diffuse throughout the region and activate specific receptors either on pre- or postsynaptic membranes. It is possible that the same receptors may be activated via this neurohumoral route as well as from specific synaptic terminals.

\section{References}

Aghajanian, G. K., and F. E. Bloom (1967) Localization of tritiated serotonin in rat brain by electron-microscopic autoradiography. J. Pharmacol. Exp. Ther. 156: 23-30.

Aghajanian, G. K., M. J. Kuhar, and R. H. Roth (1973) Serotonin-containing neuronal perikarya and terminals: Differential effects of $p$-chlorophenylalanine. Brain Res. 54: 85100.

Ajika, K., and J. Ochi (1978) Serotonergic projections to the suprachiasmatic nucleus and the median eminence of the rat: Identification by fluorescence and electron microscope. J. Anat. 127: 563-576.

Ajika, K., and T. Hokfelt (1973) Ultrastructural identification of catecholamine neurones in the hypothalamic periventricular-arcuate nucleus-median eminence complex with special reference to yuanlilative aspects. Brain Res. 57: 97-117.

Barber, R. P., J. E. Vaughn, J. R. Slemmon, P. M. Salvaterra, E. Roberts, and S. E. Leeman (1979) The origin, distribution and synaptic relationships of substance $P$ axons in rat spinal cord. J. Comp. Neurol. 184: 331-352.

Baumgarten, H. G., A. Bjorklund, L. Lachenmeyer, $\Lambda$. Nobin, and U. Stenevi (1971) Long-lasting selective depletion of brain serotonin by 5,6-dihydroxytryptamine. Acta Physiol. Scand. Suppl. 373: 000-000.

Beaudet, A., and L. Descarries (1978) The monoamine innervation of rat cerebral cortex: Synaptic and nonsynaptic axon terminals. Neuroscience 3: 851-860.

Beaudet, A., and L. Descarries (1979) Radioautographic characterization of a serotonin-accumulating nerve cell group in adult rat hypothalamus. Brain Res. 160: 231-243.

Chan-Palay, V. (1976) On the identification of $\mathrm{CAT}_{2}$ serotonin axons in the mammalian cerebellum. The roles of large granular, small, and granular alveolate vesicles in transmitter storage, discharge, and reuptake-an hypothesis. In $S I F$ Cells-Structure and Function of the Small, Intensely Fluo- 
rescent Sympathetic Cells, O. Eranko, ed., pp. 227-249, Department of Health, Education and Welfare, Washington, D.C.

Chan-Palay, V. (1978) The paratrigeminal nucleus. II. Identification and inter-relations of catecholamine axons, indoleamine axons, and substance $\mathrm{P}$ immunoreactive cells in the neuropil. J. Neurocytol. 7: 419-442.

Chiba, T., and N. Doba (1975) The synaptic structure of catecholaminergic axon varicosities in the dorso-medial portion of the nucleus tractus solitarius of the cat: Possible roles in the regulation of cardiovascular reflexes. Brain Res. 84: 3146.

Chiba, T., and N. Doba (1976) Catecholaminergic axo-axonic synapses in the nucleus of the tractus solitarius (pars commissuralis) of the cat: Possible relation to presynaptic regulation of baroreceptor reflexes. Brain Res. 102: 255-265.

Crutcher, K. A., and A. O. Humbertson (1978) The organization of monoamine neurons within the brainstem of the North American opossum (Didelphis virginiana). J. Comp. Neurol. 197: 195-222.

Dahlstrom, A., and K. Fuxe (1964) Evidence for the existence of monoamine-containing neurons in the central nervous system. Acta Physiol. Scand. 62: 5-55.

Descarries, L., A. Beaudet, and K. C. Watkins (1975) Serotonin nerve terminals in adult rat neocortex. Brain Res. 100:563588.

Eldridge, F. L., and D. E. Millhorn (1981) Central regulation of respiration by endogenous neurotransmitters and neuromodulators. Annu. Rev. Physiol. 43: 121-135.

Hokfelt, T. (1968) In vitro studies on central and peripheral monoamine neurons at the ultrastructural level. Z. Zellforsch Mikrosk. Anat. 91: 1-74.

Lidov, H. G. W., R. Grzanna, and M. E. Molliver (1980) The serotonin innervation of the cerebral cortex in the rat-an immunohistochemical analysis. Neuroscience 5: 207-227.

Maley, B., and R. Elde (1982) Immunohistochemical localization of putative neurotransmitters within the feline nucleus tractus solitarius. Neuroscience, in press.

Moore, R. Y., A. E. Halaris, and B. E. Jones (1978) Serotonin neurons of the midbrain raphe: Ascending projections. J. Comp. Neurol. 180: 417-438.

Parent, A., I. Descarries, and A. Beaudet (1981) Organization of ascending serotonin systems in the adult rat brain. A radioautographic study after intraventricular administration of $\left[{ }^{3} \mathrm{H}\right] 5$-hydroxytryptamine. Neuroscience $6: 115-138$.

Pelletier, G., F. Labrie, A. Arimura, and A. V. Schally (1974) Electron microscopic immunohistochemical localization of growth hormone release inhibiting hormone (somatostatin) in the rat median eminence. Am. J. Anat. 140: 445-450.

Pickel, V. M., T. H. Joh, and D. J. Reis (1975) Ultrastructural localization of tyrosine hydroxylase in noradrenergic neurons of brain. Proc. Natl. Acad. Sci. U. S. A. 72: 659-663.

Poitras, D., and A. Parent (1978) Atlas of the distribution of monoamine-containing nerve cell bodies in the brain stem of the cat. J. Comp. Neurol. 179: 699-718.

Richardson, K. C. (1966) Electron microscopic identification of autonomic nerve endings. Nature 210: 756.

Ruda, M. A., and S. Gobel (1980) Ultrastructural characterization of axonal endings in the substantia gelatinosa which take up $\left[{ }^{3} \mathrm{H}\right]$ serotonin. Brain Res. 184: 57-83.

Ruda, M. A., B. Allen, and S. Gobel (1981) Ultrastructural analysis of medial brain stem afferents to the superficial dorsal horn. Brain Res. 205: 175-180.

Schofield, S. P. M., and B. J. Everitt (1981) The organization of indoleamine neurons in the brain of the rhesus monkey (Macaca mulatta). J. Comp. Neurol. 197: 369-383.

Sladek, J. R., and D. L. Garver (1976) Serotonin containing perikarya and pathways in the stump-tailed macaque ( $M a$ caca arctoides). Soc. Neurosci. Abstr. 2: 475.

Steinbusch, H. W. M. (1981) Distribution of serotonin-immunoreactivity in the central nervous system of the rat-cell bodies and terminals. Neuroscience $6: 557-618$.

Steinbusch, H. W. M., A. A. J. Verhofstad, and H. W. J. Joosten (1978) Localization of serotonin in the central nervous system by immunohistochemistry: Description of a specific and sensitive technique and some applications. Neuroscience $3: 811$ 819.

Sternberger, L. A. (1979) Immunocytochemistry, Prentice-Hall, Englewood Cliffs, NJ.

Takahashi, Y., M. Tohyama, K. Satoh, T. Sakumoto, A. Kashiba, and N. Shimizu (1980) Fine structure of noradrenaline nerve terminals in the dorsomedial portion of the nucleus tractus solitarii as demonstrated by a modified potassium permanganate method. J. Comp. Neurol. 189: 525-535.

Wolf, W. A., D. M. Kuhn, and W. Lovenberg (1981) Blood pressure responses to local application of serotonergic agents in the nucleus tractus solitarii. Eur. J. Pharmacol. 69: 291299. 